\title{
The Long-Term Effects of Stand-up Paddle Boarding: A Case Study
}

\author{
Ben Schram ${ }^{1 *}$, Wayne Hing ${ }^{1}$ and Mike Climstein ${ }^{1,2}$
}

${ }^{1}$ Water Based Research Unit, Bond Institute of Health \& Sport, Bond University, Australia

${ }^{2}$ Faculty of Health Sciences, Exercise, Health, and Performance Faculty Research Group, The University of Sydney, Sydney, New South Wales, Australia

*Corresponding author: Ben Schram, Assistant Professor, Physiotherapy Program, SUP Researcher, Water Based Research Unit, Bond Institute of Health and Sport, Faculty of Health Sciences and Medicine, Bond University, Gold Coast, Qld, Australia, Tel: +617-5595-5828, Fax: +617-5595-480, E-mail: bschram@bond.edu.au

\begin{abstract}
Introduction: The association between inactivity and poor quality of life has been well documented. A major barrier to exercise is a perceived lack of time and lack of enjoyment of exercise modalities. Stand up Paddle Boarding (SUP) is an aquatic physical activity deemed easy to learn, enjoyable with a reported multitude of both physiological and psychological benefits. The long-term effects of participation in SUP however are unclear.

Case presentation: Two middle-aged participants ( 1 male, 58 yrs and 1 female, 58 yrs) over one year after continual SUP training. Participants were assessed for mass, Body Composition (BIA) and aerobic fitness, trunk muscle endurance using prone, side bridging and the Biering Sorensen and a self-rated quality of life questionnaire (WHO QoLBREF).

Results: After 12 months, the male lost $6.8 \mathrm{~kg}(-8.0 \%)$, decreased his body fat by $5 \%$ (Baseline level $=27.1 \%$-Week $52=23.7 \%$ ), and reduced his BMI by $7.34 \%$. The female lost $3.7 \mathrm{~kg}(-6.5 \%)$, had a $6.6 \%$ decrease in body fat (Baseline level $=27.1 \%$-Week $52=21.5 \%$ ) and reduced her BMI by $13.3 \%$. Trunk muscle endurance improved by $70 \%$ overall in the male and $147.5 \%$ overall in the female. Aerobic fitness improved by $25.0 \%$ in the male $(+5.5 \mathrm{ml} / \mathrm{kg} / \mathrm{min})$ and $42.3 \%$ in the female $(+12.2 \mathrm{ml} / \mathrm{kg} / \mathrm{min})$. Self-rated quality of life improved in the male $84.1 \%, 33.9 \%, 50.0 \%$, and $28.6 \%$ and in the female by $17.4 \%, 33.9 \%, 25.3 \%$ and $27.5 \%$ in the physical, psychological, social relationships and environment domains respectively.

Discussion: Long-term participation in SUP appears to be associated with improvements in overall mass, body composition, aerobic fitness, trunk muscle endurance and self-rated quality of life. Given the documented long-term physiological, musculoskeletal and psychological effects of SUP and its relative ease and accessibility, it appears to be a novel but beneficial exercise tool, which could be promoted for its wide range of positive health and fitness effects.
\end{abstract}

\author{
Keywords \\ Training intervention, Water sports, Stand up paddle boarding, \\ SUP, Health, Wellbeing
}

\section{Introduction}

Stand up Paddle Boarding (SUP) is a popular aquatic sport and recreational activity, especially in Australia. Its popularity has grown exponentially over the past decade with people riding SUP's a common sight in both the oceans and creeks throughout the country. Despite its popularity, minimal scientific evidence exists for the physiological and psychological effects of using a SUP long-term.

The sport originated in Hawaii and involves the paddler adopting a standing position and paddling with a long blade, used to provide propulsion on either side of the board [1]. The boards can range from $8-15^{\prime}$ in length, 4-8 inches thick and 26-35 inches across. It is most similar to dragon boat racing and canoeing and shares the similar phases of the SUP stroke, evident in a catch, power phase, exit and recovery.

One reason for its growth and uptake is thought to be that it is accessible, relatively easy to learn and low impact on joints [2]. It is thought to be a whole body workout with the trunk, gluteal and lower limb musculature all being involved despite the paddling motion predominately originating from the upper limb [3]. Elite SUP paddlers are now known to have high levels of aerobic and anaerobic fitness, high levels of dynamic balance and high levels of trunk muscle endurance [4].

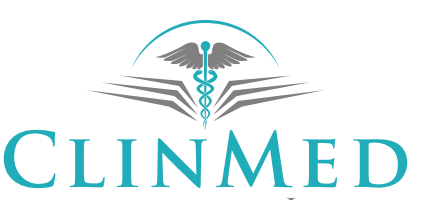

INTERNATIONAL LIBRARY
Citation: Schram B, Hing W, Climstein M (2017) The Long-Term Effects of Stand-up Paddle Boarding: A Case Study. Int J Sports Exerc Med 3:065. doi.org/10.23937/2469-5718/1510065 Received: March 30, 2017; Accepted: July 10, 2017; Published: July 12, 2017

Copyright: (C) 2017 Schram B, et al. This is an open-access article distributed under the terms of the Creative Commons Attribution License, which permits unrestricted use, distribution, and reproduction in any medium, provided the original author and source are credited. 
The short term effects of SUP as a training tool on the untrained individual show positive effects on mass, body fat, aerobic and anaerobic fitness, multidirectional trunk strength and self-rated quality of life [5]. Despite the documented positive short-term effects of SUP, the long-term effects are unclear. The purpose of this case study therefore was to document the effect of participation in SUP for two cases.

\section{Case Presentation}

Two participants who had completed an intervention study on SUP over 6 weeks maintained their participation in SUP over a full year. They had both continued to participate in SUP classes three times per week with at least 48 hours' rest between each class.

A total of two individuals ( 1 male, 58 yrs; 1 female, 58 yrs) were assessed in the Water Based Research Unit Laboratory on two consecutive days after one year of participating in SUP classes after an initial 6-week training intervention [5]. The study was approved by the University Human Research Ethics Committee (RO-1550) and each participant formally consented to taking part in the study.

For testing, participants attended the Water Based Research Unit human performance laboratory where they were assessed for height and mass on a standard medical balance scale (Seca, 700, Hamburg, Deutschland). Body composition and basal metabolic rate was assessed using bio-electrical impedance (Tanita Body Composition Analyzer MC-980MA, Illinois, USA) as this has previously been shown to accurately estimate body composition [6].

A continuous graded exercise test using a SUP ergometer (KayakPro SUPErgo, Miami, FL, USA) was used to determine maximal aerobic power (relative and $a b-$ solute). The SUP Ergometer is elevated on springs to replicate the instability of SUP paddling on water. This laboratory assessment has previously been shown to correlate highly to field based measures [7]. Maximal aerobic power $\left(\mathrm{V}_{2 \max }\right)$ was determined using an automated expired gas analysis system (Parvomedics TrueOne 2400 metabolic system, East Sandy, Utah, USA) which was calibrated prior to each test. The expired-gas-analysis system meets Australian Institute of Sport accreditation standards for precision and accuracy. The gas analysis software was configured to breath by breath however $\dot{\mathrm{O}}_{2 \max }$ was determined from the average of 30 seconds of max data collected.

The SUP ergometer $\mathrm{VO}_{2 \max }$ protocol involved participants starting at an initial power output of $5 \mathrm{~W}$ with a 2 $W$ increase each minute until volitional exhaustion. Participants were instructed to paddle as per normal, free to alternate paddling on each side ad libitum.

On a subsequent visit to the laboratory, maximal anaerobic power was determined using the same SUP ergometer (KayakPro SUPErgo, USA). Participants were allowed to choose their preferred paddling side on the ergometer to ensure that an indication of their maximal power output could be reached. Participants then paddled maximally for 10 seconds from a stationary start. The maximal power was then determined using specialised software incorporated into the SUP ergometer (eMonitor Pro 2 KayakPro, New Rochelle, NY, USA) which was interfaced with a computer. Other measures include anaerobic power parameters which included distance covered in 10 seconds and peak anaerobic speed. Participants' heart rates were monitored with a 12 lead ECG via telemetry during both maximal tests. A minimum of two days and a maximum of three days were allowed between testing days.

Trunk muscle endurance assessments were performed as per McGill in which the flexors of the spine were assessed with a prone bridge, the lateral flexors with the side bridge and the extensors with the Biering Sorensen test [8]. The tests were terminated when the participant could no longer hold the horizontal position as determined by the tester and the time was recorded.

Finally, a self-rated quality of life questionnaire (WHO-QoL Bref UK edition) was completed by the participants pre and post training program. It comprises 26 items across four domains of Physical Health, Psychological Health, Social Relationships and Environment. For example, items in the Physical Health domain include energy and fatigue and pain and discomfort, while the Psychological domain includes items such as body image, appearance and self-esteem. The Social Relationships domain relates to items including personal relationships while the Environment domain includes items such as participation in and opportunities for recreational activities. This questionnaire was administered to assess the effect of a SUP intervention on self-rated quality of life measures.

\section{Case 1}

A sedentary 58 -year-old male $(188.8 \mathrm{~cm}, 96.9 \mathrm{~kg}$, BMI $=30.7 \mathrm{~kg} / \mathrm{m}^{2}$ ) expressed an interest in SUP due to a history of surfing. Measures at all time points can be seen in Table 1. Initial measures showed $27.1 \%$ body fat and $66.4 \mathrm{~kg}$ muscle mass. Prior to the intervention, his trunk muscle endurance was $78.12 \mathrm{sec}$ in the prone position, $44.06 \mathrm{sec}$ on the right, $32.76 \mathrm{sec}$ on the left and 63.55 sec for the lumbar erectors. His aerobic fitness was 21.6 $\mathrm{ml} / \mathrm{kg} / \mathrm{min}$ with a maximal power output of $9.3 \mathrm{~W}$. His self-rated Quality of Life questionnaire scored a 44/100 for Physical Health, 56/100 for Psychological Health, $50 / 100$ for social relationships and $63 / 100$ for environment. Accepted norms for a male in this age group have been reported at $82.6 \pm 15.7,73.7 \pm 13.2,74.4 \pm 15.2$ and $79.0 \pm 11.1$ for each domain respectively [9].

Upon subsequent assessment after six weeks of training on a SUP body composition had changed mini- 
Table 1: Subject results over the 12 month period. $B M I=$ Body Mass Index, $(R)=$ right, $(L)=$ left.

\begin{tabular}{|c|c|c|c|c|c|c|}
\hline \multirow[b]{2}{*}{ Parameter } & \multicolumn{2}{|c|}{ Week 0} & \multicolumn{2}{|c|}{ Week 6} & \multicolumn{2}{|c|}{ Week 52} \\
\hline & Male & Female & Male & Female & Male & Female \\
\hline Mass (kg) & 96.9 & 57.2 & 96.1 & 56.7 & 90.4 & 53.5 \\
\hline Body fat (\%) & 27.1 & 28.1 & 27.3 & 25.9 & 23.7 & 21.5 \\
\hline Muscle mass (kg) & 66.4 & 38.7 & 66.9 & 39.9 & 67.1 & 39.9 \\
\hline BMI $\left(\mathrm{kg} / \mathrm{m}^{2}\right)$ & 30.7 & 24.8 & 30.4 & 24.5 & 28.6 & 21.5 \\
\hline Prone trunk endurance (s) & 78.1 & 101.5 & 117.4 & 107.0 & 123.1 & 162.3 \\
\hline (R) Trunk endurance (s) & 44.1 & 22.2 & 75.5 & 31.2 & 103.7 & 36.9 \\
\hline (L) Trunk endurance (s) & 32.8 & 10.9 & 25.6 & 35.7 & 55.0 & 47.1 \\
\hline Biering sorensen (s) & 63.6 & 87.5 & 63.0 & 121.3 & 70.2 & 201.5 \\
\hline Aerobic fitness (ml/kg/min) & 21.6 & 14.9 & 24.4 & 17.8 & 27.1 & 21.2 \\
\hline Anaerobic fitness (W) & 9.6 & 3.7 & 11.6 & 5.6 & 14.3 & 9.0 \\
\hline Physical health & 44 & 69 & 63 & 75 & 81 & 81 \\
\hline Psychological health & 56 & 56 & 69 & 69 & 75 & 75 \\
\hline Social relationships & 50 & 75 & 56 & 94 & 75 & 94 \\
\hline Environment & 63 & 69 & 75 & 81 & 81 & 88 \\
\hline
\end{tabular}
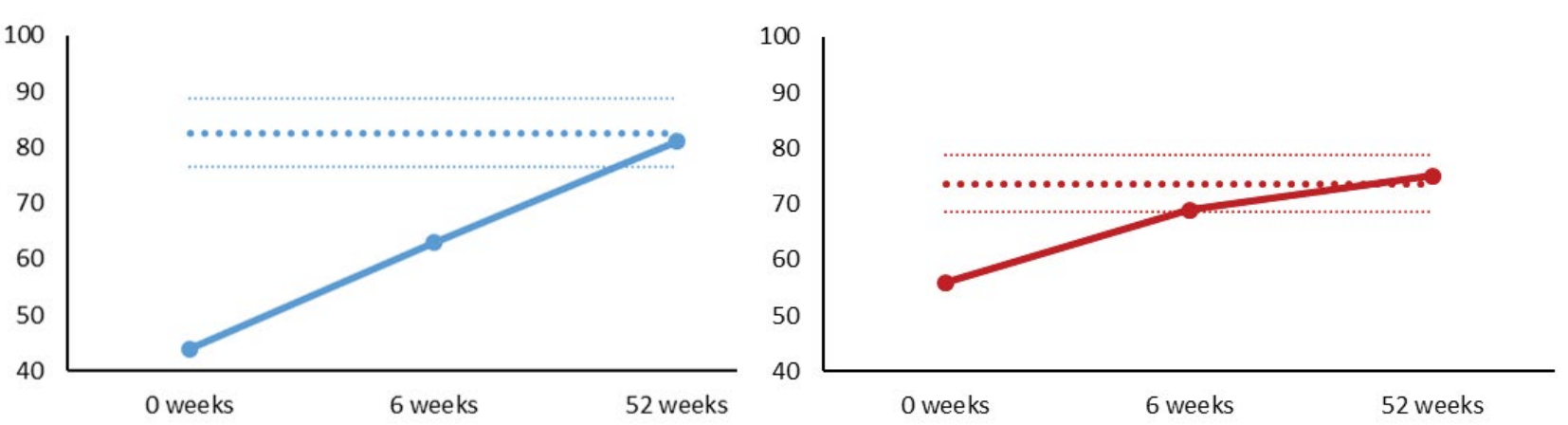

$\longrightarrow$ Physical Domain
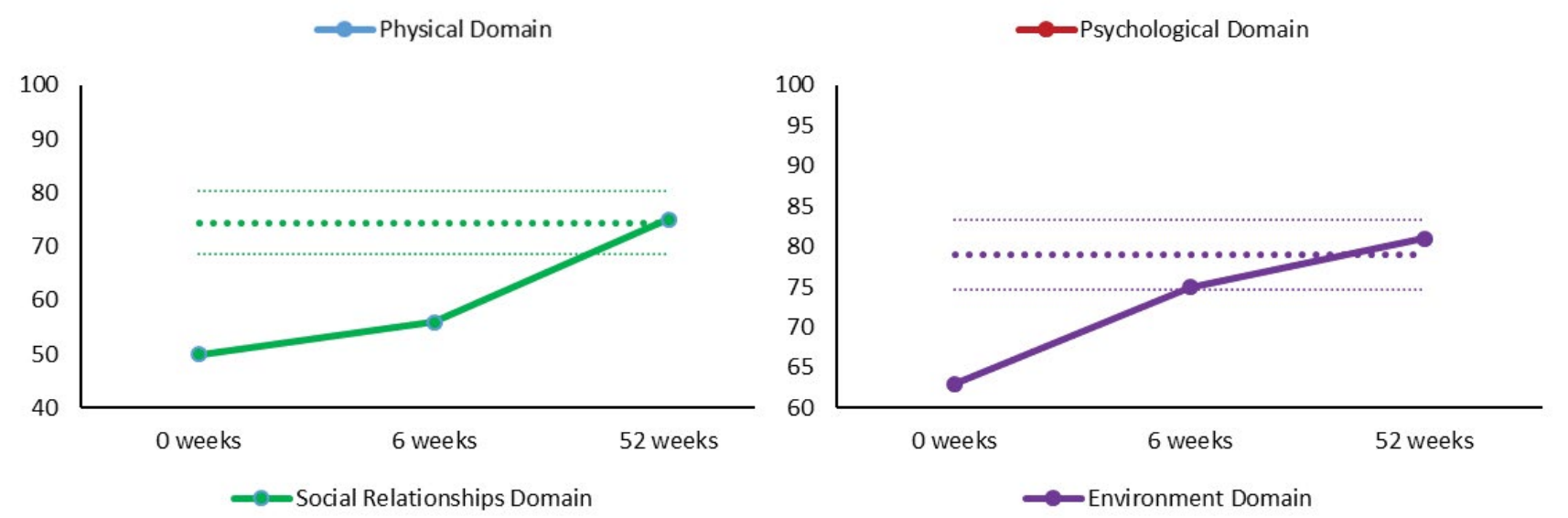

Figure 1: Self-rated quality of life results with age predicted norms and $95 \%$ confidence intervals.

mally with the subject losing only $800 \mathrm{~g}(-0.83 \%)$, gaining $0.2 \%$ body fat, $500 \mathrm{~g}$ of muscle $(+0.8 \%)$ and decreasing his BMI by $0.3 \mathrm{~kg} / \mathrm{m}^{2}(-0.8 \%)$. A $39.3 \mathrm{sec}(+50.3 \%)$ increase in prone trunk endurance, $31.4 \mathrm{sec}$ increase (+ $71.2 \%)$ in right sided and $7.2 \mathrm{sec}$ decrease $(-22.0 \%)$ in left sided endurance along with a relatively unchanged (- 0.1\%) Biering Sorensen measure was found. Aerobic fitness had increased by $2.8 \mathrm{ml} / \mathrm{kg} / \mathrm{min}(+13.0 \%)$ and anaerobic power output increased by $2 \mathrm{~W}(+20.8 \%)$. All domains of the self-rated Quality of Life Questionnaire had improved with Physical Health increasing by 19 points $(+43.2 \%)$, Psychological Health increasing by 13 points $(+23.2 \%)$, Social Relationships increasing by 6 points $(+12.0 \%)$ and Environment increasing by 12 points $(+19.1 \%)$.
After the full year of training, the male had lost a total of $6.8 \mathrm{~kg}(-8 \%)$, decreased his body fat by $5 \%$, and reduced his BMI by $2.1 \mathrm{~m} / \mathrm{kg}^{2}$ (- 6.8\%). His trunk muscle endurance improved by $45.0 \mathrm{sec}$ in the prone position, 59.6 secs in the right sided position, 22.2 secs in the left sided position and 6.6 secs in the Biering Sorensen position. His aerobic fitness improved by $5.5 \mathrm{ml} / \mathrm{kg} / \mathrm{min}$ and anaerobic fitness by $4.7 \mathrm{~W}$. As displayed in Figure 1, results of the self-rated quality of life questionnaire showed increases of 37 points (+ 84.1\%) in the Physical Health domain, 19 points (+ $33.9 \%$ ) in the Psychological Health domain and 25 points (+ $50.0 \%$ ) and 18 points (+ 28.6\%) in the Social Relationships and Environment domains respectively. At 12 months post intervention, all self-rated measures were within the age predicted $95 \%$ confidence intervals for accepted norms [9]. 


\section{Case 2}

An inactive 58-year-old female whose initial measures were mass of $57.2 \mathrm{~kg}$, height $152 \mathrm{~cm}$ and BMI 24.5 $\mathrm{kg} / \mathrm{m}^{2}$ also participated in SUP classes for a 52 week period. All measures can be seen in Table 1 . She initially had $28.1 \%$ body fat and $38.7 \mathrm{~kg}$ of muscle. Her prone trunk endurance was $101.5 \mathrm{sec}, 22.2 \mathrm{sec}$ on the right side, $10.9 \mathrm{sec}$ on the left side and $87.5 \mathrm{sec}$ in the Biering Sorensen position. Her aerobic fitness was recorded at $14.9 \mathrm{ml} / \mathrm{kg} / \mathrm{min}$ and anaerobic fitness of $3.7 \mathrm{~W}$. Her self-rated Quality of Life Questionnaire was rated at $69 / 100$ in the Physical Health Domain, 56/100 in the Psychological Health Domain, 75/100 in the Social Relationships domain and 69/100 in the Environment Domain. Normative values for a female in this age group are $78.6+17.7$ in the physical domain, $73.9 \pm 12.4$ in the psychological, $72.1 \pm 20.3$ in the Social Relationships domain and $75.5 \pm 14.8$ in the Environment domain [9].

After six weeks of training on a SUP, mass had decreased by $500 \mathrm{~g}(-0.9 \%)$, body fat had decreased by $2.2 \%$ and gained $1.2 \mathrm{~kg}(+3.1 \%)$ of lean muscle. These figured decreased her BMI by $0.3 \mathrm{~kg} / \mathrm{m}^{2}(-1.2 \%)$. Prone trunk endurance increased by $5.5 \mathrm{sec}(+5.3 \%)$, right side by $9 \mathrm{sec}(+40.5 \%)$, left by $24.8 \mathrm{sec}(+225.7 \%)$ and the Biering Sorensen by $33.8 \mathrm{sec}(+38.6 \%)$. Aerobic and anaerobic fitness were increased by $2.8 \mathrm{ml} / \mathrm{kg} / \mathrm{min}$ (+ 19.5\%) and $1.9 \mathrm{~W}(+51.4 \%)$ respectively. Her self-rated quality of life increased by $6(+8.7 \%)$ points in the Physical domain, 13 points $(+23.2 \%)$ in the psychological domain, 19 points $(+25.3 \%)$ in the Social Relationships Domain and 12 points $(+17.4 \%$ ) in the Environment domain.
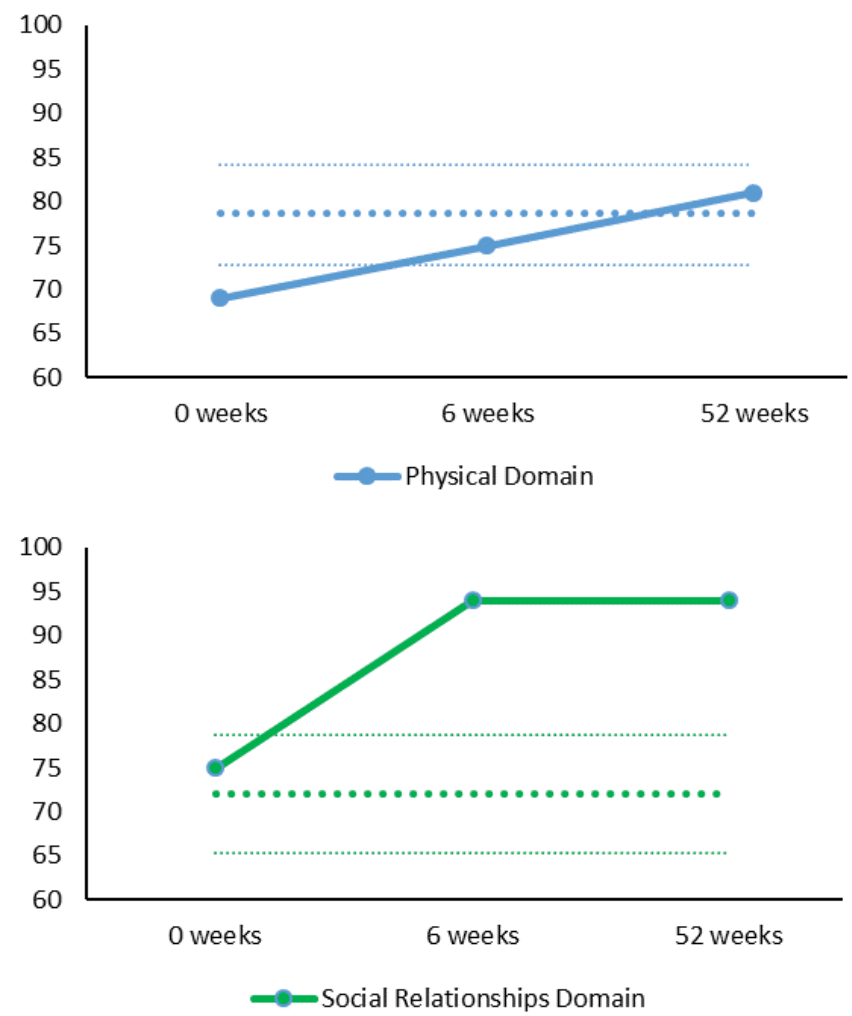

After the year of SUP training, the females mass had decreased by $3.7 \mathrm{~kg}(-6.5 \%)$, body fat had decreased by $6.6 \%$, muscle mass increased by $1.2 \mathrm{~kg}(+3.1 \%)$ and $\mathrm{BMI}$ had decreased by $3.3 \mathrm{~kg} / \mathrm{m}^{2}(-13.3 \%)$ when compared to the initial measures. Prone endurance had increased by 60.8 secs, right sided by $14.7 \mathrm{sec}$, left side by 36.2 sec and Biering Sorensen by 114 secs. Aerobic fitness increased by $6.3 \mathrm{ml} / \mathrm{kg} / \mathrm{min}$ and anaerobic fitness by 5.3 $W$. As seen in Figure 2, self-rated quality of life results increased by 12 points $(+17.4 \%)$ in the physical, 19 points $(+33.9 \%)$ in the psychological, 19 points $(+25.3 \%)$ in the social relationships and 19 points $(+27.5 \%)$ in the environment domains. While both the physical and psychological domain results at 12 months were within the 95\% confidence intervals for age predicted norms, both social relationships and environment domains are seen to be well above the age predicted norms (Figure 2).

\section{Discussion}

The purpose of this case study was to document the chronic effects of participation in SUP for two individuals. To our knowledge, this is the only data available, which has monitored the effects of SUP over a 12-month period. A longer period of participation in SUP was seen to increase health and fitness gains even more than the initial 6 week period measured in this case study.

The weight loss of the subjects in this compare well to other studies which have found weight loss of $7 \%$ in females and $10 \%$ in males after 1 year follow up utilising an exercise and lifestyle intervention with type 2 diabetes patients [10]. Lifestyle interventions inclusive of dietary changes have seen decreases in weight in males of
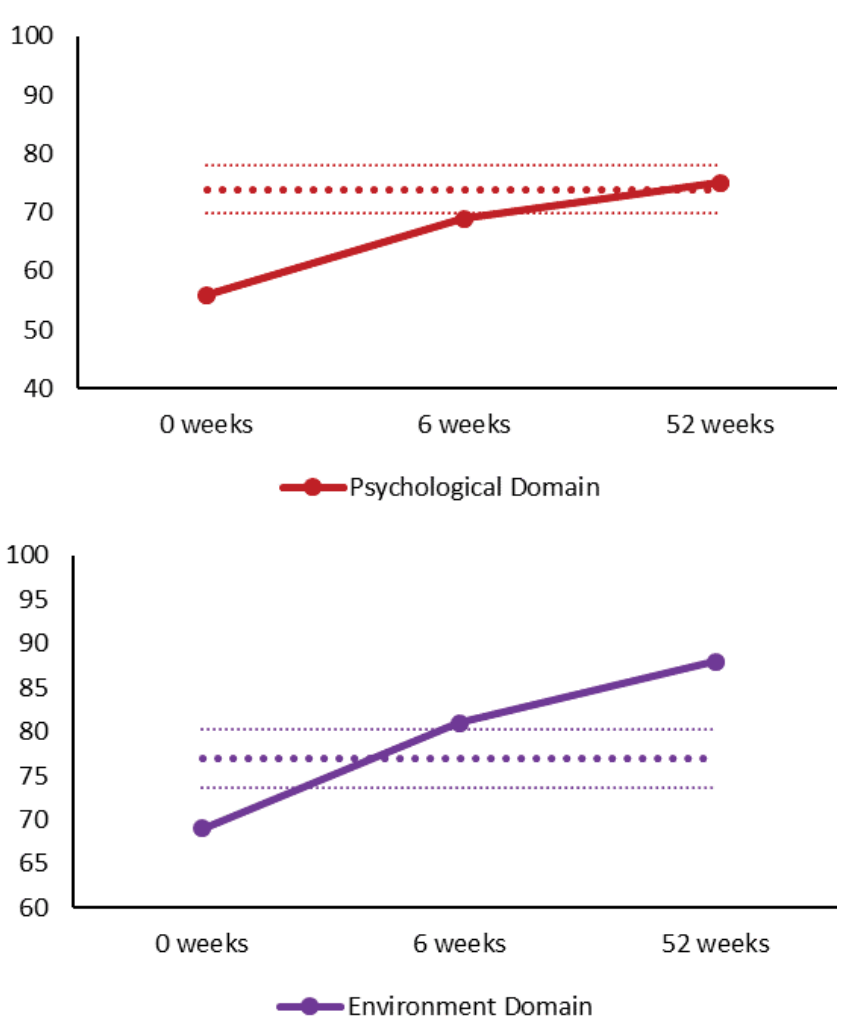

Figure 2: Results from the self-rated quality of life questionnaire with norms and $95 \%$ confidence intervals. 
$5 \mathrm{~kg}, 1.7 \%$ body fat and $3.9 \mathrm{~kg}$ weight loss and $2 \%$ body fat in previously obese females [11]. It should be noted that the female in this study with an initial BMI of 24.8 $\mathrm{kg} / \mathrm{m}^{2}$ is classified as normal. Despite this, the female in this study was still able to lose $6.6 \%$ body fat over the duration of the year. Elevated adipose tissue in the middle aged, has been linked to hypertension, diabetes, cognitive dysfunction, cancers and atherosclerosis which can lead to heart attacks and strokes [12] highlighting the importance of maintaining healthy adipose levels.

Trunk muscle endurance was seen to improve in all directions in the tests performed in this study. Despite minor improvements in case 1's Biering Sorensen results, Previous studies have demonstrated improvements in the Biering Sorensen of 56.9 secs at one year follow up with 'functional restoration' training incorporating aerobic and resistance exercise for 5 weeks in back pain patients [13]. Few studies have followed trunk muscle endurance over an entire year, however studies of shorter durations have found increases in the Biering Sorensen ranging from $30.34 \%$ to $46.95 \%[14,15]$. The improvements in trunk endurance are important as a lack of endurance has been found to be a major reason for the recurrence and chronicity of low back pain [16]. It is thought that this may lead to clinical instability of lumbar segments [17] and strength training of the extensors of the spine has been shown to be effective in treating musculoskeletal disorders [18].

The large improvements in $\mathrm{VO}_{2 \max }$ in this study are most probably attributed to the low baseline measures of the participants. Large increases in aerobic fitness due to training have previously been associated with low baseline measurements of fitness [19]. Previous studies have reported increases in aerobic fitness of $5.7 \mathrm{ml} / \mathrm{kg} /$ min with 12 months of walking/jogging endurance training three times per week for 45 minute sessions at $60 \%$ of heart rate reserve [20]. For females specifically, other studies have reported an $11 \%$ increase in $\mathrm{VO}_{2 \max }$ in previously sedentary females (average age 58-61 yrs) over a year of walking, cycling and strength training [21]. Other investigators have found increases of $\mathrm{VO}_{2 \max }$ of $7 \mathrm{ml} / \mathrm{kg} /$ min with aerobic training and $10 \mathrm{ml} / \mathrm{kg} / \mathrm{min}$ in aerobic and strength training combined [22].

A significant finding during the one-year follow up was the improvement in self-rated quality of life as measure by the WHO-QoL BREF. Early changes are seen in both the physical and psychological health domains with minimal changes in the social relationships and environment domain after six weeks. It is thought that the social aspect of SUP and relationship building amongst its participants may not be elicited in the shorter six-week timeframe of the prior intervention study. Facets in these two domains which may be influenced by participation in SUP include 'social support' and 'participation in and opportunities for recreation/leisure activities'. It is believed the plateau in the female's social relationship domain evident in Figure 2 may be due to a ceiling effect. Given the detrimental effects of sedentary lifestyles on numerous non-communicable diseases such as diabetes mellitus, osteoporosis, some forms of cancer, heart disease, stroke and hypertension [23], the multitude of positive results of this study and prior research over a shorter period should be acknowledged [5]. A common barrier for people not participating in adequate levels of physical activity is that they are time poor [24]. Given the multitude of benefits on fitness, strength and self-rated quality of life demonstrated in the case study, it would appear that SUP could be a well-placed option for those seeking an exercise with numerous positive health and fitness benefits.

In the two cases presented who continued to utilise SUP as a training tool, ongoing health and wellness benefits were found. For these two individuals, continuing an exercise regime of just three times per week utilising a SUP was enough to maintain health and fitness gains, aid in weight loss, improve fitness, trunk endurance and self-rated quality of life, especially in the social relationship and environmental domains.

\section{References}

1. Ruess C, Kristen KH, Eckelt M, Mally F, Litzenberger S, et al. (2013) Stand up Paddle Surfing-An Aerobic Workout and Balance Training. Procedia Engineering 60: 62-66.

2. Schram B (2015) Stand up paddle boarding : an analysis of a new sport and recreational activity. Bond University: Gold Coast, QId.

3. Ruess C, Kristen KH, Eckelt M, Mally F, Litzenberger S, et al. (2013) Activity of Trunk and Leg Muscles during Stand up Paddle Surfing. Procedia Engineering 60: 57-61.

4. Schram B, Hing W, Climstein M (2016) Profiling the sport of stand-up paddle boarding. J Sports Sci 34: 937-944.

5. Schram B, Hing W, Climstein M (2016) The physiological, musculoskeletal and psychological effects of stand up paddle boarding. BMC Sports Science, Medicine and Rehabilitation 8: 32.

6. Lukaski HC, Bolonchuk WW, Hall CB, Siders WA (1986) Validation of tetrapolar bioelectrical impedance method to assess human body composition. J Appl Physiol (1985) 60: 1327-1332.

7. Schram B, Hing W, Climstein M (2016) Laboratory-and field-based assessment of maximal aerobic power of elite stand-up paddle-board athletes. IJSPP 11: 28-32.

8. McGill SM, Belore M, Crosby I, Russell C (2010) Clinical tools to quantify torso flexion endurance: Normative data from student and firefighter populations. Occupational Ergonomics 9: 55-61.

9. Hawthorne G, Herrman H, Murphy B (2006) Interpreting the WHOQOL-Brèf: Preliminary Population Norms and Effect Sizes. Social Indicators Research 77: 37-59.

10. Gallagher D, Heshka S, Kelley DE, Thornton J, Boxt L, et al. (2014) Changes in adipose tissue depots and metabolic markers following a 1-year diet and exercise intervention in overweight and obese patients with type 2 diabetes. Diabetes Care 37: 3325-3332.

11. Nakade M, Aiba N, Suda N, Morita A, Miyachi M, et al. 
(2012) Behavioral change during weight loss program and one-year follow-up: Saku Control Obesity Program (SCOP) in Japan. Asia Pac J Clin Nutr 21: 22-34.

12. Tchkonia T, Morbeck DE, Von Zglinicki T, Van Deursen J, Lustgarten J, et al. (2010) Fat tissue, aging, and cellular senescence. Aging Cell 9: 667-684.

13. Roche-Leboucher G, Petit-Lemanac'h A, Bontoux L, Dubus-Bausière V, Parot-Shinkel $E$, et al. (2011) Multidisciplinary intensive functional restoration versus outpatient active physiotherapy in chronic low back pain: a randomized controlled trial. Spine 36: 2235-2242.

14. Carter JM, Beam WC, McMahan SG, Barr ML, Brown LE (2006) The effects of stability ball training on spinal stability in sedentary individuals. J Strength Cond Res 20: 429-435.

15. Sekendiz B, CuÄŸ M, Korkusuz F (2010) Effects of Swissball core strength training on strength, endurance, flexibility, and balance in sedentary women. J Strength Cond Res 24: 3032-3040.

16. Adedoyin RA, Mbada CE, Farotimi AO, Johnson OE, Emechete AA (2011) Endurance of low back musculature: normative data for adults. J Back Musculoskelet Rehabil 24: 101-109.

17. Panjabi MM (1992) The stabilizing system of the spine. Part II. Neutral zone and instability hypothesis. J Spinal Disord 5: 390-396.
18. Kollmitzer J, Ebenbichler GR, Sabo A, Kerschan K, Bochdansky $T$ (2000) Effects of back extensor strength training versus balance training on postural control. Med Sci Sports Exerc 32: 1770-1776.

19. Astorino TA, Schubert MM, Palumbo E, Stirling D, McMillan DW, et al. (2013) Magnitude and time course of changes in maximal oxygen uptake in response to distinct regimens of chronic interval training in sedentary women. Eur $\mathrm{J} \mathrm{Appl}$ Physiol 113: 2361-2369.

20. Scharhag-Rosenberger F, Meyer T, Walitzek S, Kindermann W (2009) Time course of changes in endurance capacity: a 1-yr training study. Med Sci Sports Exerc 41: 1130-1137.

21. Irwin ML, Yasui Y, Ulrich CM, Bowen D, Rudolph RE, et al. (2003) Effect of exercise on total and intra-abdominal body fat in postmenopausal women: A randomized controlled trial. JAMA 289: 323-330.

22. Chow R, Harrison JE, Notarius C (1987) Effect of two randomised exercise programmes on bone mass of healthy postmenopausal women. Br Med J (Clin Res Ed) 295: 1441-1444.

23. George ES, Kolt GS, Duncan MJ, Caperchione CM, Mummery WK, et al. (2012) A review of the effectiveness of physical activity interventions for adult males. Sports Med 42: 281-300.

24. Kessler HS, Sisson SB, Short KR (2012) The potential for high-intensity interval training to reduce cardiometabolic disease risk. Sports Med 42: 489-509. 